\section{ECT treatments}

Sir: Hughson \& Lyons (Psychiatric Bulletin, August 1994, 18, 507) suggest that psychiatrists are "superstitious, obsessional or both", and quote as evidence that significantly more patients receive even numbers of ECT treatments.

The truth is, however, more boring than fiction. The majority of units perform ECT twice a week, and consultants have their ward rounds weekly. Since it is invariably the consultant who initiates and terminates ECT, then in most cases there will be an even number of treatments between ward rounds. The occasional weekly treatment or intrusive bank holiday can act as a confounder.

Undoubtedly some of us are superstitious or obsessional, while others need no prompting to behave oddly, but better evidence than this is needed if we are to be objective.

RICHARD BARNES, Whiston Hospital, Prescot, Merseyside

Sir: In the interests of objectivity, we considered rating our colleagues on superstition, obsessionality and oddness, but feared that if we did so, they might want to get even with us.

A. V. MARK HUGHSON and DONALD LYONS, Leverndale Hospital, Glasgow C53 7TU

\section{Fitness to drive}

Sir: It is common in old age psychiatry to be asked to advise on the fitness to drive of a patient with a putative diagnosis of dementia. With regard to this diagnosis, the current guidelines of the Driver and Vehicle Licensing Authority state, "There is no single marker to determine fitness to drive but it is likely that driving may be permitted if there is retention of ability to cope with the general day to day needs of living, together with adequate levels of insight and judgement" (DVLA, 1993).

We could contend that this directive is excessively vague and falls to recognise the clinical reality of the (often rapidly) progressive nature of all dementing illnesses. Indeed it has been our experience that attempting to persuade the demented patient who is lacking in insight not to drive can be most difficult. We suggest that once the diagnosis of dementia is established discontinuation of driving sooner rather than later should be advised. (The patient with insight is obviously much more likely to be receptive to such counsel than one without).

We recognise the hardship this loss of mobility and independence can occasion and regard it as part of our function as an old age service to explore with patients and their families alternative (but safer) modes of transport with a view to minimising any privation.

At a Glance Guide to the Current Medical Standards of Fitness to Drive DVLA. Swansea (September 1993) p. 15.

JOHN CORISH, Psychiatry of Old Age and LINDA SuTch, Community Psychiatric Nurse, Richmond, Twickenham \& Roehampton Healthcare NHS Trust, Twickenham TW $3 H Q$

\section{An ethical dilemma in psychotherapy}

Sir: I read with interest the paper 'An ethical dilemma in psychotherapy' by Holmes et al, and the annexed commentary by Adshead \& Smith (Psychiatric Bulletin, August 1994, 18, 466-468). However, I disagree with their statement that "It is interesting how in the present case the intake panel's (i.e. the resource allocators's) countertransference, which reflected the patient's own family experience, led them to opt for the decision that gave David less and other future patients more."

This statement which apparently embodies the central thesis of this paper is not only a reflection of an outdated deterministic dogma, but ethically unsound as well. Without denying the importance of the unconscious and its heuristic and clinical value, the unconscious should not be used as a scheme assisting people to deny their responsibilities for their action, that is, through seeking justifications by resorting to a part of their psyche, over which, by definition, they usually have no control.

The panel was not an automaton governed exclusively by any form of unconscious process, be it counter-transference or otherwise. Otherwise there was no need for a panel at all (at least until all its members had gone through long-term psychoanalysis in order, it is hoped, to free themselves of all their blind spots). To deprive the panel of its potential to act freely in psychological terms within a specific reality framework and to reduce it function to that of a helpless robot is a futile task, a task which becomes a real ethical dilemma when reputable psychological theories are (ab)used to confer credibility on it.

The authors failed, as well, to comment on the benefits of counter-transference. This was crucial in the sense of not abasing the process of counter-transference in and of itself and acknowledging people's potential to use mental operations, conscious or unconscious, constructively.

TALAL AL RUBAIE, Psychotherapist in private practice, 41 Denison Close, East Finchley, London N2 OJU 